\title{
Feedback structure of cliff and shore platform morphodynamics
}

\author{
Andres Payo • Jim W. Hall • Mark E. Dickson • Mike J. A. Walkden
}

Received: 31 May 2014 / Revised: 19 September 2014 / Accepted: 22 September 2014 /Published online: 1 October 2014

(C) Springer Science+Business Media Dordrecht 2014

\begin{abstract}
It has been suggested that studies of geomorphological systems should identify potential system feedbacks, determine their direction of influence, and assess their relative importance. In this paper we show how a core set of processes and feedback loops can be distilled from existing literature on rock coast morphodynamics. The structure has been represented using Causal Loop Diagrams and a methodology to estimate the strength of a single feedback loop is presented. The backwearing erosion rate (cliff horizontal erosion) has been found to be controlled by at least four feedback loops; three balancing (cliff toe wave energy depletion, ground-water pore pressure diminution and cliff deposit protection) and one positive loop (abrasion enhancement). The downwearing erosion rate (vertical erosion) has been found to be controlled by at least three balancing feedback loops (weathering limited, shear depletion, cover-protection). Mean sea level directly influences the downwearing rate, through the water depth relative to the wave base, and indirectly influences the backwearing erosion rate through the wave
\end{abstract}

\footnotetext{
A. Payo $(\bowtie) \cdot J$. W. Hall

Oxford University Centre for the Environment, South Parks Road, Oxford OX1 3QY, UK

e-mail: andres.payo@ouce.ox.ac.uk

J. W. Hall

e-mail: jim.hall@eci.ox.ac.uk

M. E. Dickson

School of Environment, University of Auckland, 10 Symonds St, Auckland Private Bag 92019, New Zealand

e-mail:m.dickson@auckland.ac.nz

M. J. Walkden

WSP Group, Keble House, South Parks Road, Southernhay Gardens, Exeter EX1 1NT, UK

e-mail: Mike.Walkden@WSPGroup.com
}

energy dissipation that determines the amount of energy reaching the cliff toe. The offshore wave non-linearity parameter is proposed to capture the complex interaction between waves and shore platform geometries. The strength of the cliff toe energy depletion loop is assessed by reasoning on its causal pathway and found to be $\mathrm{O}\left(-10^{-10}\right.$ to $\left.-10^{-4}\right)$ for poorly lithified rock coasts. By understanding how the individual and overall feedback strengths are influenced by different future environmental and human intervention scenarios we could provide better assessment at the time scales needed for coastal management.

Keywords Framework · Causality analysis · Causal loops diagrams $\cdot$ Feedback factor

\section{Introduction}

Stakeholders worldwide need to anticipate how shorelines will respond to accelerated sea level rise at time scales as large as 50 to 100 years. As coastal evolution models for rocky coasts become increasingly complex, it is important to have a basic theoretical framework of how different processes interact with each other and influence the changes and responses to interventions at different stages of development. Ashton et al. (2011) have provided a general theoretical framework for the response of a wide range of cliffed rocky shores to sea level rise by studying equilibrium conditions, and normalizing posterior recession rate and sea-level rise with prior conditions (see Fig. 1). They noted that the general type of response to sea-level rise will be determined by the coast type, environmental drivers, and dominant processes, such as sediment flux, wavedriven erosion, and weathering dominated systems in 

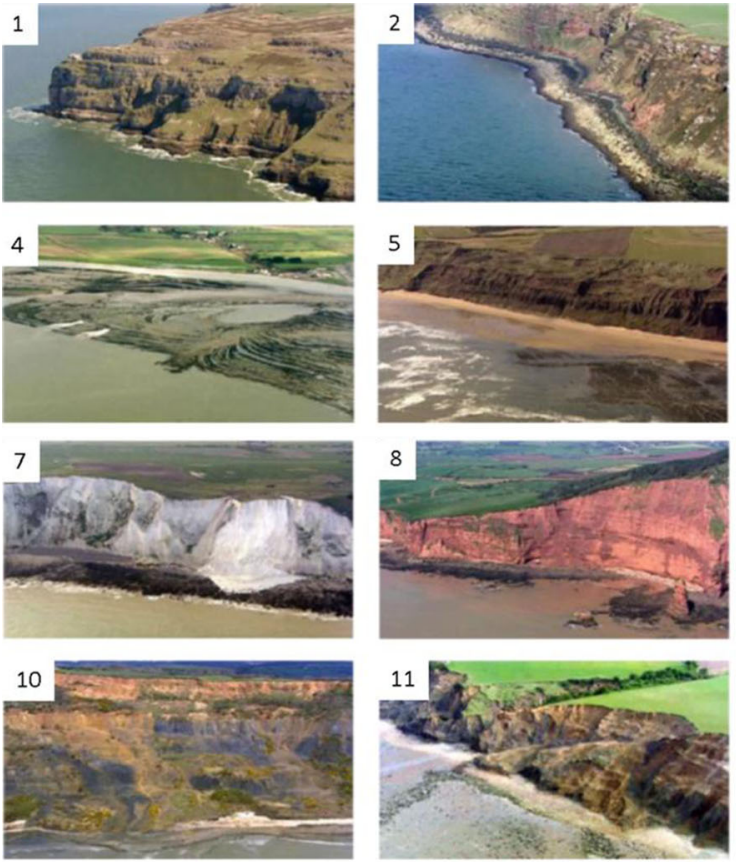

Fig. 1 The response of rocky coastal systems to sea level change will depend on the main processes involved and the rate of sea level rise Panels 1 to 11 shown different types of rock coasts around UK: (1-3) cliffs fronted by shore platforms of varied width; (4) extensive shore platform; (5) cliff fronted by sandy beach and shore platform; (6) sandy beach between cliffed headlands; (7) chalk cliff fronted by shore platform; (8) cliff fronted by small beach and shore platform; (9) cliff fronted by sandy beach; (10) landslide complex fronted by mixed sand/gravel beach;

which exposure time is crucial. They concluded that the most common behaviour of cliffed coasts is likely to be that of a 'damped system' in where negative feedbacks reduce the rate of cliff recession as shore profiles are exposed to waves over time. However, this response characterises equilibrium conditions, whereas at decadal timescales cliffed coasts will be responding to sea-level rise in ways that are far from equilibrium. Hence, further work is needed to characterize the transient stage to improve the information available to coastal managers. Here we use the Causal Loop approach as a structured means of synthesising knowledge of processes to reason about long term geomorphic development.

To identify the likely response of cliffed coasts to sea-level rise during the transient stage there is a need to understand which processes are dominant. Feedback process analysis is a valuable tool in this respect. Phillips (2009) proposed '4Rs' (recursion, response, resilience, resistance) as a theoretical framework to understand change in geomorphic systems by identifying potential feedbacks, determining their signs, and assessing their relative importance. Lane (2013), by analogy with lessons learned from climate modelling, argued that in geomorphology there is the need for a great number of feedbacks to be identified and appreciated. Since the
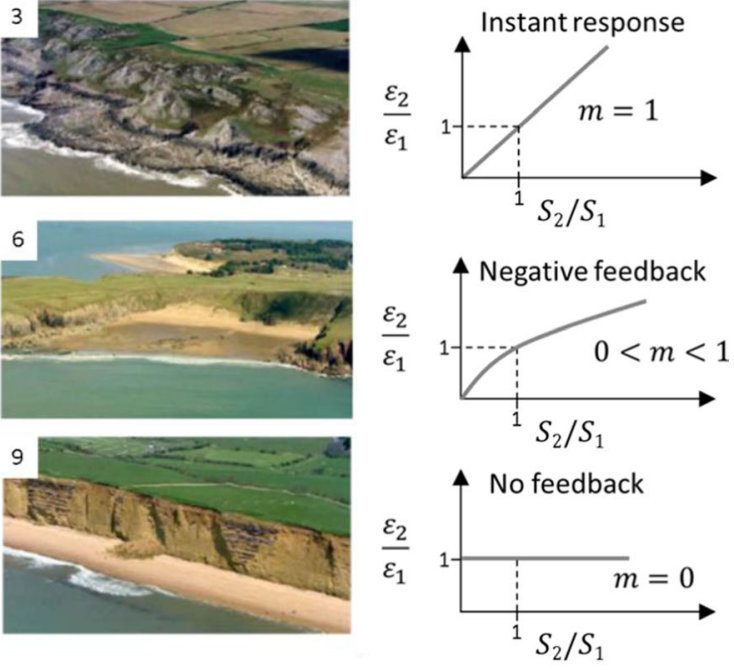

$$
\frac{\varepsilon_{2}}{\varepsilon_{1}} \propto\left(\frac{S_{2}}{S_{1}}\right)^{m}
$$

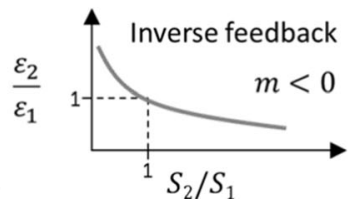

(11) clay cliff fronted by sandy beach and unconsolidated shore platform. Four different responses proposed by Ashton et al. (2011) (right), where $\varepsilon_{1} / \varepsilon_{2}$ and $S_{1} / S_{2}$ are the ratios of future and prior recession rates and sea level rise respectively. The rate of cliff retreat will depend not only on the absolute sea level change, but also the rate of sea level change and dominant coastal processes. Figure modified from (Masselink and Russell 2010)

comprehensive review of Stephenson (2000) more effort has been dedicated to understanding shore platform dynamics. As a result, while linking processes at different scales with cliff and platform erosion is still a field of active research, it is now possible to identify a key set of feedback processes from existing literature (Naylor et al. 2010), which are formalized and expanded upon in this paper.

In this paper a causal loop analysis is proposed to (1) describe the overall feedback structure that controls the cliff and shore platform system, and (2) provide a methodology for the assessment of the strength of a given feedback loop. First, the feedback structure is derived from pre-existing literature on the dynamics of rocky coasts, whether strongly or poorly lithified. The causal loop diagram (CLD) convention is used to represent the loop structure. This provides an evidencelinked map of our current process understanding and remaining knowledge gaps. In the second part of the paper, we investigate the strength of the feedback loop between platform widening and cliff-backwearing by reasoning on the processes involved in the loop. This provides a worked example of how the feedback framework can be used both as a conceptualization tool, and also to assess how improved process understanding might be translated in better informed coastal management. 


\section{Methodology}

\section{Causal loop analysis}

The feedback structure of cliff dynamics is distilled from the literature and represented using CLD convention (Lane 2000). A list of symbols used in the present paper is provided in an (Appendix). In this paper the main processes related to shore platform rates of erosion (see Fig. 2) are synthesized. Erosion is understood in broader terms as the decrease of consolidated shore platform and cliff mass (i.e. sub aerial or submerged) as talus, beach material, or suspended sediment. To simplify the problem space, and retain consistency with the literature, erosion is described in its horizontal (backwearing) and vertical (downwearing) components. Shore platform width and slope are emergent properties of an eroding rocky coastal system. Both sub-aerial weathering and erosive marine process may be important, the relative efficacy of which depends on various local factors (Trenhaile 2008).

The symbolic convention used in this review is presented in Fig. 3. For the sake of clarity, a minimal set of symbols is used to capture causality and feedback loop structure. These include:

- Two types of variables: (1) state variables (stocks, levels, attributes) (e.g., beach width, sea level, sediment size, threshold wind velocity for initiating sediment transport), (2) rate variables (flows) (e.g. rate of shoreline change, sediment transport rate).

- Positive $(+)$, negative $(-)$ or influence $(+/-)$ links. Links connect two variables (e.g. $\mathrm{X} \rightarrow \mathrm{Y}$ ) and represent the answer to the question if $X$ increases, would this cause $Y$ to increase or decrease? Links are positive if $\mathrm{dy} / \mathrm{dx}>0$ or negative if $\mathrm{dy} / \mathrm{dx}<0$. When the answer to this question is unknown or ambiguous it is represented as an influence link.

- Causal pathways. We can reason about the influence of one variable on another variable indirectly connected to it by examining the signs along their causal pathway (e.g., two negatives, whether adjacent or not, will act to reverse each other). Loops in a causal loop diagram indicate feedback in the system being represented. In this case, changes cascade through other factors so as to either amplify (reinforcing feedback; products of signs positive) or damp the original change (balancing feedback; products of signs negative).

Feedback factor assessment

The concept of feedbacks has proved helpful in the idealized model domain, but extrapolation to the real world is complicated. For example in the area of climate modelling Klocke et al. (2013) provides a review of different metrics for physical climate feedbacks and strength assessment methods. The assessment of the feedback strength involves the assessment of partial derivatives between pair-wise linked variables. In climate modelling, partial derivatives can hardly be obtained from observations, due to many interfering processes that are difficult to separate from the background variability and also difficult to isolate in a model. In geomorphology examples of qualitative stability assessment of the system based on the feedback loop structure go back to at least the early 1980 s (Phillips 2006; Slingerland 1981). The stability of the system (or conditions under which it is stable) can be determined if historical reconstructions or field observations, identify the key system components and the positive, negligible, or negative links between them. This often takes the form of a signed digraph, network model, or box-and-arrow diagram. These can be translated into an interaction matrix, and the stability may be determined based only on the qualitative $(+,-, 0)$ links.

In absence of feedback, the total change in the state variable is just the initial change (Total effect=Direct Effect). If there is a feedback process then, with one pass around the feedback loop, the direct effect will be enhanced or damped by a feedback factor $g$ such that Total Effect=Direct Effect $+(\mathrm{g})$ (Direct Effect). If $g$ is positive, then the feedback is reinforcing
Fig. 2 Decrease of cliff and shore platform mass is expressed as backwearing and downwearing rates which are understood as measurable components of the overall erosion. Cliff failure might be either induced by wave undercutting (toppling) or shearinduced (landsliding). Both failures contribute to overall erosion through the backwearing erosion rate

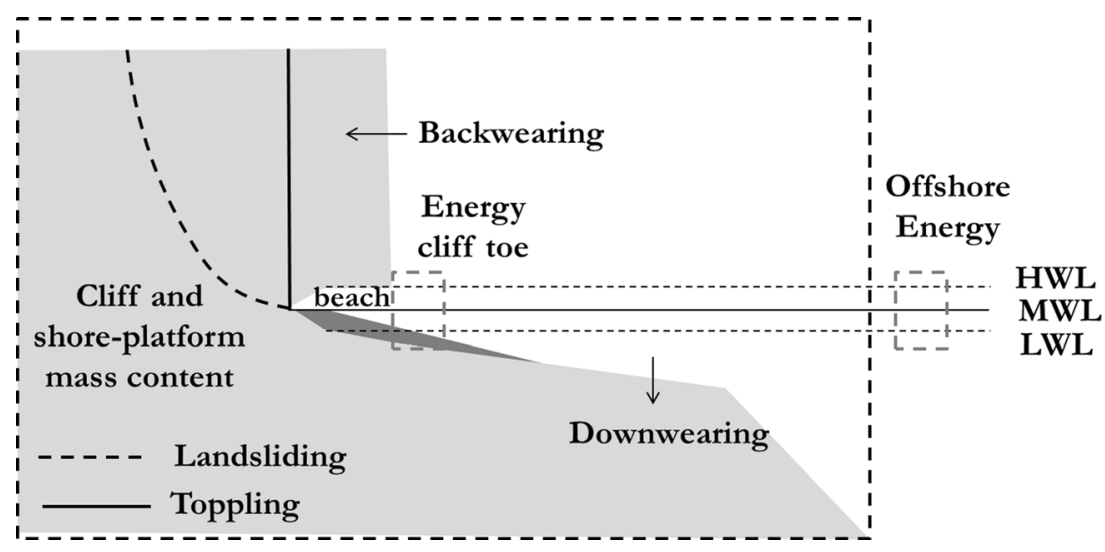


Fig. 3 Convention used to represent the causal loop diagrams in this paper. (a) Symbol convention and (b) example with two positive and one negative feedback loop. In this example, the behaviour of state variable $X_{2}$ will depend on the strength of the positive feedback loop with $\mathrm{p}_{1}$ and the negative feedback loop with $\mathrm{p}_{2}$
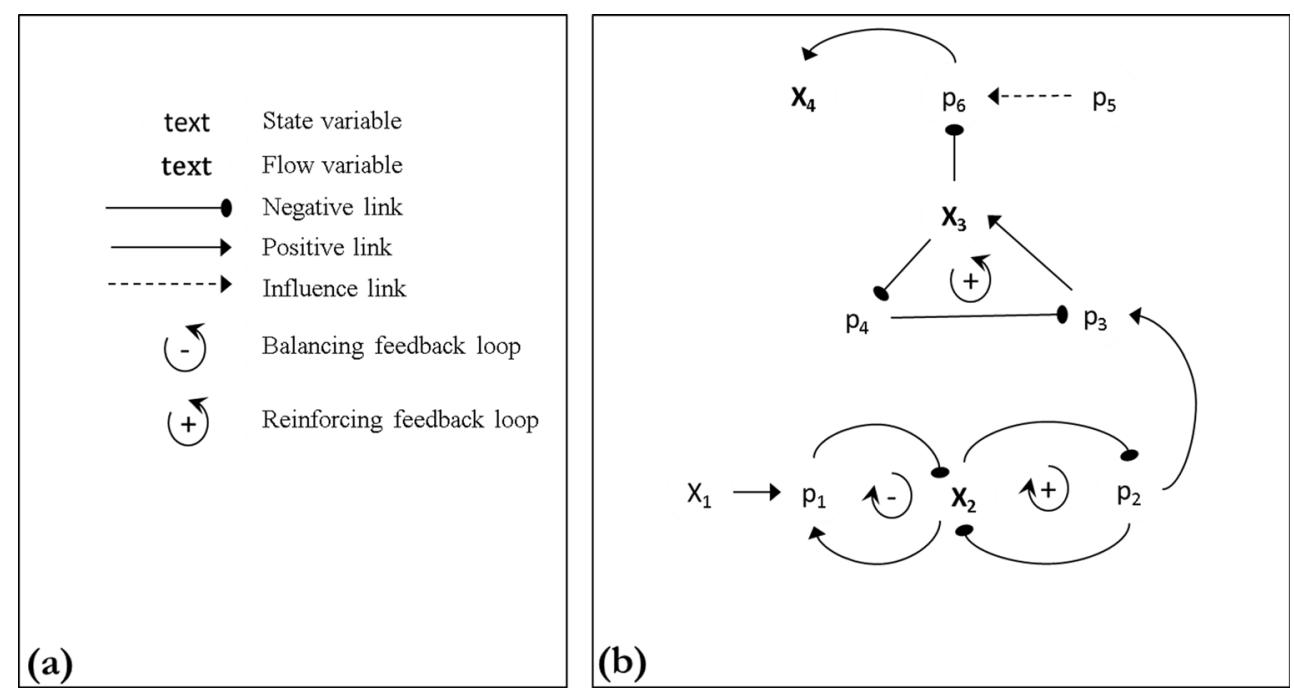

the initial disturbance, whereas if $g$ is negative, the feedback tends to reduce (balance) the initial change. In practice, there will be infinitely many passes around the feedback loop, and each leads to another factor of $g$ multiplying the input: Total Effect $=($ Direct Effect $)\left(1+\mathrm{g}+\mathrm{g}^{2}+\mathrm{g}^{3}+\cdots\right)=($ Direct Effect $) /(1-$ g) if $g<1$ (Harte 2001). Given a dynamic model that incorporates a feedback mechanism, and assuming that either the state equation $F$ is linear or the incremental change is small relative to the unperturbed value, the overall feedback factor $g$ can be calculated as the summation of the partial feedback factors of each loop as shown in Fig. 4., where $X$ is a variable whose state depends on a set of variables $p_{i}$. This functional relationship is given by $F$. For the example shown, $X$ is controlled by two feedback loops ( $g_{1}$, reinforcing and $g_{2}$ balancing) and the direct effect of another variable $\left(p_{4}\right)$. Since $p_{4}$ has only a direct effect on $X$, it does affect the change of $X$ but not the overall feedback strength, $g$. The overall feedback factor can be estimated as a linear addition of the feedback factor for the inth feedback loop, $g_{i}$.

\section{Results}

Feedback loop structure of cliff dynamics

From the literature reviewed, the main processes and feedback loops that determine cliff erosion and shore platform evolution are summarized below. How each of these processes is represented using CLDs is first individually presented (see Figs. 5 and 6) and at the end of the section collapsed into an overall feedback loop structure (see Fig. 7.).

The main processes and feedback loops considered are:

- Lithology, mechanical strength, discontinuities. Backwearing and downwearing erosion rates are influenced by rock resistance, which depends on rock lithology, mechanical strength, and the presence of discontinuities (Naylor and Stephenson 2010; Sunamura 1994)

- Shear depletion loop. Wave energy dissipation on a shore platform is mostly controlled by the water depth
Fig. 4 Causal Loop Diagrams provide a formal framework to assess the relative and absolute strength of feedback loops on a given state variable. A reinforcing and balancing loop influencing the state variable $\mathrm{X}$ is shown in a. The relative strength of the feedback loops is represented by $\mathrm{g}_{1}$, and $\mathrm{g}_{2}$. The overall feedback strength can be estimated as the sum of these two feedbacks as shown in $b$. The total effect of a change given change in $\mathrm{X}$ is inversely related to the overall feedback factor strength
Conceptual model

$$
X=F\left(p_{1}(X), p_{2}(X), p_{3}(X), p_{4}\right)
$$

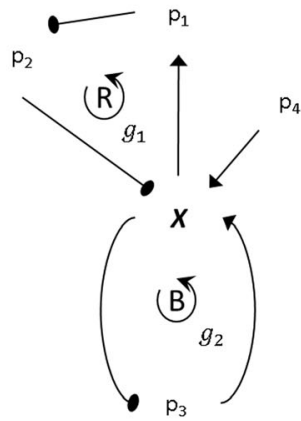

(a)

\section{Feedback factor}

$$
\begin{gathered}
g=\sum_{i} \frac{\partial F}{\partial p_{i}} \frac{\partial p_{i}}{\partial X}=\sum_{i} g_{i} \\
g=\frac{\partial X}{\partial p_{1}} \frac{\partial p_{1}}{\partial p_{2}} \frac{\partial p_{2}}{\partial X}+\frac{\partial X}{\partial p_{3}} \frac{\partial p_{3}}{\partial X}=g_{1}+g_{2}
\end{gathered}
$$

What will be the Total Effect if $X+\Delta X$ ?

$$
\text { Total Effect }{ }^{*}=\frac{\Delta X}{1-g}
$$

If $0<g<1:$ Total Effect $>$ Direct Effect, Reinforcing If $g<0$ : Total Effect $<$ Direct Effect, Balancing If $g>1$ : Instability

(b) *Valid if $\frac{\Delta x}{X} \leq 0.1$ or $F$ is linear 
Fig. 5 Initial conceptualization of the feedback structure of cliff and shore platform evolution. Panel (a) shows the three main types of shore platform after Sunamura (1992). Platform width is represented for the sloping and near horizontal platforms. Panel (b) shows the feedback structure. The influence of lithology, fatigue and discontinuities on the erosion rates is acknowledged with a dashed line arrow (influence link) to illustrate that these factors have some influence, but their sign (positive or negative) is not shown
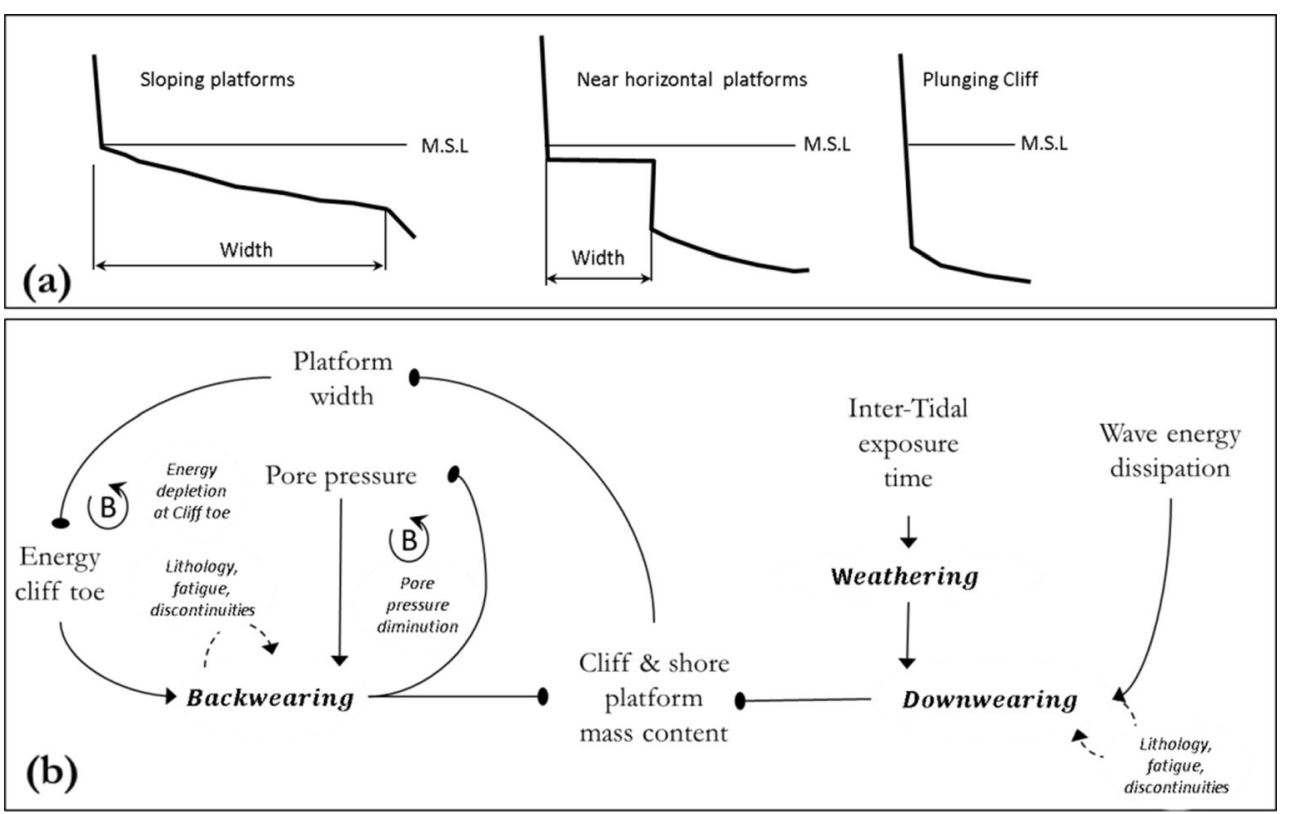

(Thornton and Guza 1982). An increase in the water depth due to downwearing, reduces the energy dissipation rate and therefore the downwearing erosion rate. A change on the energy dissipation rate over the platform indirectly influences the energy reaching the cliff toe.

- Cliff toe energy depletion. Backwearing of the cliff toe precludes further erosion by widening the shore platform that dissipates energy more effectively.

- Feedback between wetting-drying cycles and platform downwear. Higher numbers of wetting and drying cycles on platform surfaces have been linked to increased downwearing rates (Stephenson and Kirk 2000). With other factors held constant, a vertically eroding platform increases its water depth, which reduces the number of wet-dry cycles, balancing back the erosion rate.

- Cover protection loop. Fine sediment eroded from the cliff and platform may be removed from the system as suspended sediment, whereas beach-grade sediment may be deposited at the cliff toe. Beach sediments might impede direct wave attack, reducing backwearing rates, and cover the shore platform reducing downwearing rates (Castedo et al. 2012; Trenhaile 2005; Walkden and Hall 2005).

- Abrasion enhancement loop. Beach material may also increase the abrasive capacity of the incoming waves, both at the cliff toe (Robinson 1977; Trenhaile 2005) increasing the backwearing rate, and also on the platform surface increasing the downwearing rate (Walkden and Hall 2005).

- Feedback loop between pore pressure release and backwearing erosion rate. The build-up and release of pore pressure has been identified (measured and modelled) as a balancing feedback of backwearing rate (Castedo et al. 2012; Fort et al. 2000). The associated zone of depressed pore pressure to cliff backwearing prevents the pore pressure build-up over time.
Fig. 6 The offshore wave nonlinearity parameter has been found to clarify the changes on the reflection, transmission and dissipation coefficients (Massel and Gourlay 2000). The offshore wave non-linearity parameter is related with the platform geometry through the representative depth, $h_{r}$

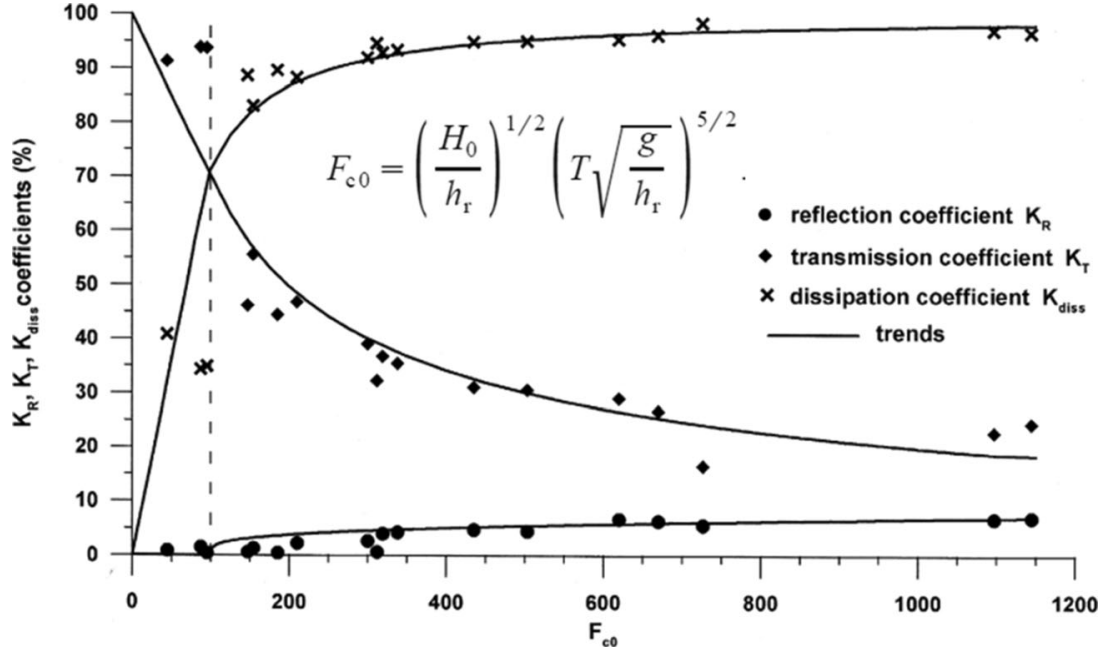




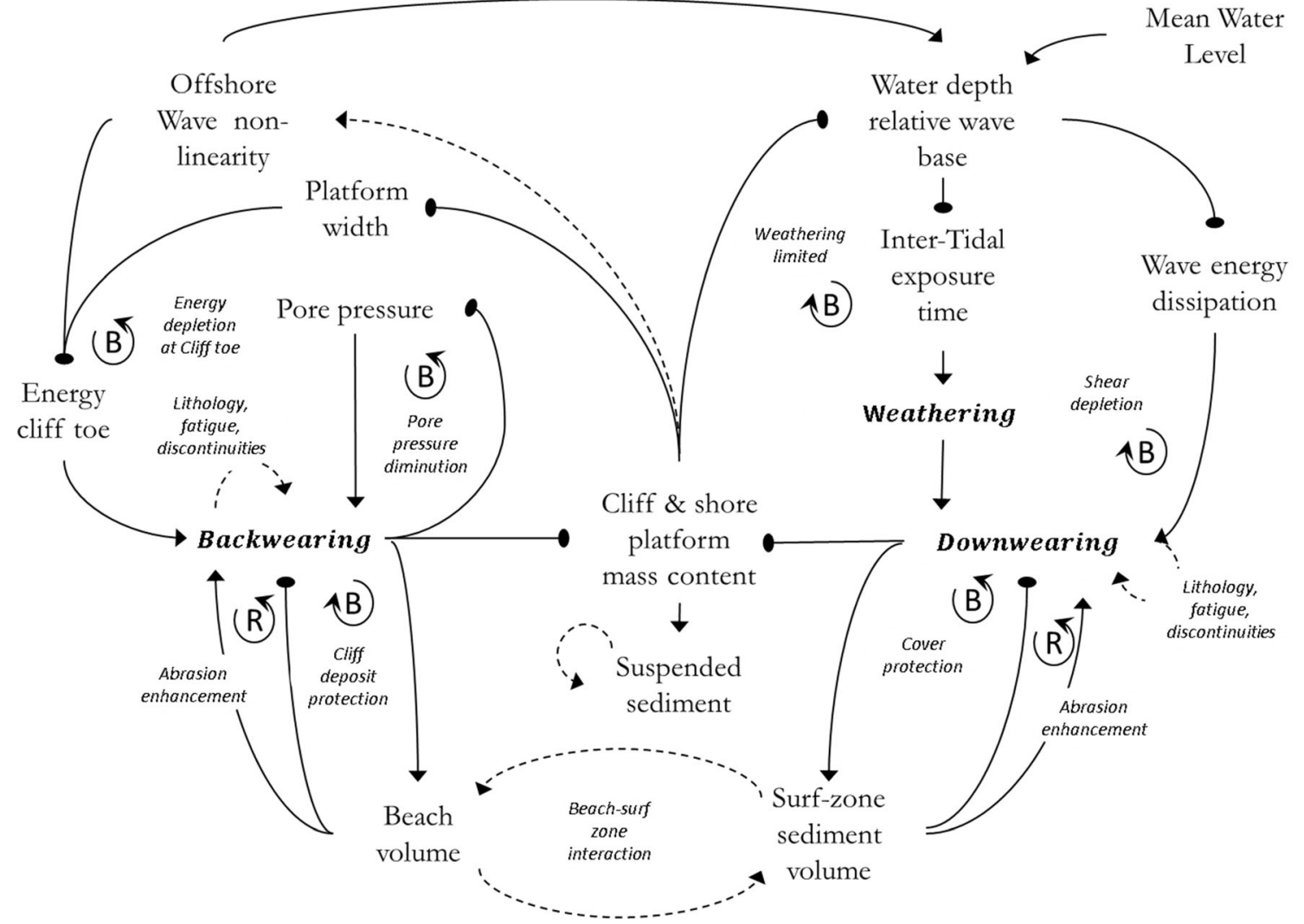

Fig. 7 Overall shore platform feedback structure including the beachplatform interaction. Beach volume is defined as the mobile sediment volume from the berm crest landward and surf volume is the mobile bed sediment from the berm crest seaward up to the zone were waves are no

Figure 5 represents an initial subset of the processes that have been identified from existing literature. By definition, an increase of both backwearing and downwearing erosion rates decreases the cliff and shore platform mass content and is therefore represented as a negative influence link. To avoid cluttering the diagram, the influence of lithology, mechanical strength and discontinuities on the erosion rates is acknowledged as an influence link (dashed line), but their sign (positive or negative) is not shown in the diagram. This implies that, well-known processes such as fatigue due to temperature (frost/defrost cycles) are not explicitly represented in the diagram but implicitly included within this influence link. Platform downwearing due to weathering can be accomplished by a variety of mechanisms, but the general efficacy of platform-weathering processes is often modulated by tidal wetting and drying cycles (Trenhaile 2005). This is represented as a positive link between intertidal exposure time and weathering rate. Downwearing of the intertidal platform, in the absence of abrasive material and bioerosional organisms, has been attributed generally to weathering and removal of the fine-grained debris by waves (Porter et al. 2010). Most of the mechanical downwearing of the submerged platform is due to breaking waves, the downwearing erosion rate has been often conceptualized as a decaying function of water depth longer breaking. Fine material eroded from the shore platform increases the amount of suspended sediment. The existence of other feedbacks, which further control beach and surf-zone bed sediment, are not shown here but acknowledged by the dashed lines

(Sunamura 1992; Trenhaile 2005). Since the exponential decay with depth is controlled by the wave energy dissipation rate, the influence of wave breaking is represented as a positive link between wave energy dissipation rate and downwearing. An increase in the energy reaching the cliff toe increases the backwearing rate (positive influence) by increasing undercutting. The influence of the debris at the toe of the cliff on the backwearing erosion rate is lately included within the overall feedback loop structure. The rainfall accumulated as groundwater increases the pore pressure eventually triggering the shear failure of the cliff (Castedo et al. 2012). Fort et al. (2000) found that the associated unloading resulted in a zone of the depressed pore pressures which temporarily prevent deep-seated instability of the oversteepened cliff. This is represented as negative link between backwearing and pore pressure resulting in a balanced loop between backwearing erosion rate and pore pressure. The backwearing erosion rate is balanced back by widening the platform. Platform width is understood as the horizontal distance between the cliff toe and the sea edge at which offshore waves start to be transformed by interaction with the bottom. Given that the wave energy at the gravity band frequency decreases shoreward from the platform sea edge (Sunamura 1992) an increase of platform width will have a negative 
influence in the energy reaching the cliff toe. The cliff toe energy depletion loop is further explained in the next section.

\section{Role of shore platform geometry}

The influence of shore platform geometry (i.e. gradient, elevation and width) has long been identified as an important control on the rate of cliff and platform erosion, but it has been only broadly conceptualized. For instance, platform gradient has been studied in association with tidal range and despite a great deal of attention, the link between platform morphology and tidal range and duration remains ambiguous (Stephenson 2000). Simple conceptualizations of wave propagation on simulation models proven useful are not applicable to typical geometries. For instance, Trenhaile (2010) used linear wave theory to propagate offshore waves and compute the bed shear stress over cohesive clay platforms. While for gently sloping shore platforms (e.g. cohesive, mixed clay-sand), linear theory might suffice, but it does not capture the rapid bottom orbital velocity changes observed on irregular geometries that occur on hard-rock coasts. The typical Type-B morphology of hardrock coasts includes an abrupt seaward scarp and a nearhorizontal to gently sloping ( 1 deg) platform. This morphology is similar to that which occurs on coasts with coral reef platforms. Theoretical and experimental observations on such shores suggests that the so-called non-linearity wave parameter, $F_{c o}$, based on deep water wave height and a representative depth over the reef-platform geometry is a suitable parameter for classifying wave transformation on a number of platform geometries (Massel and Gourlay 2000; Swart and Loubser 1979). The non-linearity parameter increases with offshore wave height and period, and decreases with the representative water depth. The representative depth might be defined as the still water depth over the reef-edge. An increase of $F_{c o}$ increases the wave energy dissipation and decreases the wave transmission (i.e. decreases wave energy onshore) (Fig. 6.).

While the use of the wave non-linearity parameter is relatively new within the rock coast morphodynamic literature (e.g. Ogawa 2012), we found this concept useful to represent the overall feedback structure. An increase of the offshore wave non-linearity parameter in any case decreases the wave energy reaching the cliff toe (i.e. due to an increase in reflection and dissipation) and, is represented as a negative link among $F_{c o}$ and Energy at cliff toe. On the shore platform, an increase on the offshore non-linearity parameter increases the water depth relative to the wave base. The wave base is defined here as the water depth at which the wave bottom shear-stress might potentially induce bed erosion. The wave base increases with the wave period and wave height. The complex interaction between long waves and, short waves and platform geometry might lead to counter-intuitive energy transformation at the cliff toe which is yet not fully understood (Dickson et al. 2013; Ford et al. 2012, 2013; Payo and Muñoz-
Perez 2013). The unknown influence of the cliff and shore platform geometry (elevation, gradient and width) is acknowledged by an influence link between the mass content and the offshore wave non-linearity parameter in Fig. 7.

The overall shore platform feedback structure including beach-platform interaction is shown in Fig. 7. The bed material eroded from cliff backwearing and platform downwearing is deposited as beach sediment. Fine material eroded from the cliff and shore platform increases the suspended sediment content and is lost from the system. Beach and surf-zone sediment protects the cliff and shore platform through balancing feedback loops (cliff deposit protection and cover protection loops). Cliff-foot deposits can provide protection to the cliff or they can act as abrasives inducing a reinforced feedback loop (abrasion enhancement loop). The beach and surf-zone volume are further controlled (not shown in Fig. 7) by the alongshore sediment transport gradient and the balance between diffusive and anti-diffusive processes (Murray and Ashton 2013). The role of mean water level and offshore wave energy in the feedback structure is shown within the overall feedback structure. If the water depth relative to the wave base increases, the influence of the surface water waves on the platform surface decreases. This is represented as a positive link between the offshore wave non- linearity parameter and the relative water depth to the wave base. If mean sea water levels rise too quickly, an eroding platform can be abandoned if the wave base no longer reaches the platform. By reasoning on the influence pathway linking cliff and shore platform mass content with the relative water depth to wave base two balancing feedback loops are identified, termed here the weathering limited and the shear depletion loops. A decrease of mass content due to vertical erosion, increases the relative water depth that, for a given tidal range, decrease the intertidal exposure time (starting from mass content the pathways read as $--++-=-$ ). A decrease of mass content also reduces wave erosional potential, by reducing energy dissipation rate, balancing back the initial downwearing erosion rate.

\section{Strength of cliff toe energy depletion loop}

In the following the strength of the cliff toe energy depletion loop is estimated by reasoning on the current understanding of the causal pathway. Based on the feedback structure identified in the previous section and the methodology proposed, three main quantities need to be estimated to assess the strength of this balancing loop (Fig. 8.): (1) how the backwearing erosion rate (E) increases with the energy reaching the cliff toe; (2) how the platform width (W) increases with the backwearing erosion rate; (3) how the energy at the cliff toe decreases with the platform width. The way these estimates are obtained is described below. Ultimately, the feedback factor strength is then obtained from the product of these three quantities. 
Fig. 8 Assessing the strength of the balancing $(g<0)$ cliff-toe energy depletion loop is reduced to three main questions. Left panel shows the conceptual model of platform widening where cliff and shore platform mass wasting $(\mathrm{dM} / \mathrm{dt})$ is represented by the backwearing component (E). Right panel shows the three main questions that need to be estimated

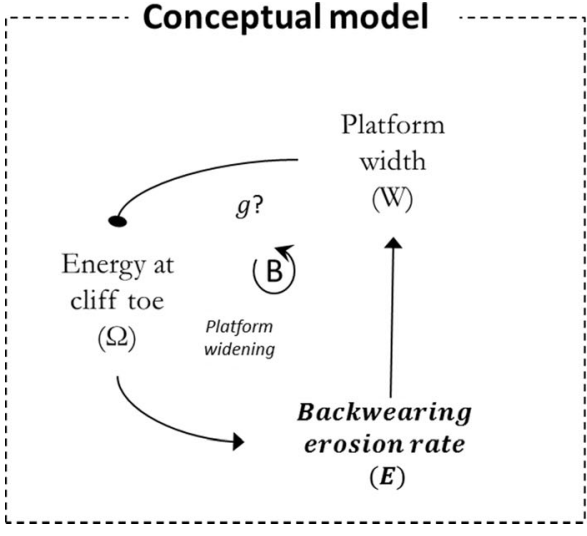

Feedback factor

$g=\frac{\partial E}{\partial \Omega} \frac{\partial W}{\partial E} \frac{\partial \Omega}{\partial W}=?<0$

$\frac{\partial E}{\partial \Omega}>0 \quad$ 1) How $E$ increases with $\Omega$ ?

$\frac{\partial W}{\partial E}>0 \quad$ 2) How $W$ increases with $E$ ?

$\frac{\partial \Omega}{\partial W}<0 \quad$ 3) How $\Omega$ decreases with $W$ ?
Influence of incident wave energy on backwearing erosion rate.

Hackney et al. (2013), proposed and validated with field data a simple relationship between soft cliff erosion rate and wave energy. Based on the premise that an 'Accumulated Excess Energy' (AEE) parameter can be used to represent the process of hydraulic erosion at the base of the cliff, the relationship between backwearing erosion rate and wave energy is given by;

$E=\int_{t=0}^{t}\left[f\left(\left(\Omega(t)-\Omega_{c}\right)+c_{2}\right)\right] d t$

Where $\mathrm{E}=$ the amount of erosion $(\mathrm{m})$ during the time interval $\mathrm{t}, \Omega=$ applied wave energy $\left(\mathrm{J} / \mathrm{m}^{3}\right), \Omega_{\mathrm{c}}=$ threshold wave energy $\left(\mathrm{J} / \mathrm{m}^{3}\right)$ required to initiate erosion, and $c_{2}$ is a calibration coefficient. The average energy of a wave per unit surface area, $\Omega$, is;

$\Omega=\frac{1}{8} \rho g H_{s}^{2}$

Where $\Omega$ is energy $\left(\mathrm{J} / \mathrm{m}^{3}\right), \rho$ is the density of sea water $\left(\mathrm{kg} / \mathrm{m}^{3}\right), g$ is the gravitational potential energy of the wave $\left(\mathrm{m}^{2} / \mathrm{s}\right)$ and $H_{s}$ is the significant wave height (m). The time interval is bounded to the underlying theoretical concept of Basal End Point Control (BEPC). The principal implication of BEPC, that the rate of retreat is governed by hydraulic activity at the toe, applies over time scales encompassing multiple cycles of slumping and toe erosion. Accordingly, it is important to ensure that the calibration of any model based on the principles of BEPC is conducted over a large enough temporal scale (i.e., multiple cycles of hydraulically controlled undercutting, mass wasting, and removal of the slumped debris) to ensure that hydraulic activity at the toe is the dominant factor controlling slope retreat. For a time scale of about 10 year, and for the different wave environments and geologies around the Isle of Wight and Suffolk coast in UK, Hackney et al. (2013) found that Eq. (1) is best fitted by;

$E=c_{1}\left(\Omega(t)-\Omega_{c}\right)+c_{2}$

Where $c_{1}$ is a fitted constant of the order of $10^{-6}$ to $10^{-7}$ for the predominantly clay-cliff study sites. They further notice that the failure of Eq. (1) to produce significant relationships in the more resistant units may indicate that the $\sim 10$-year timeframe employed may be too short. The change of erosion rate with changes on the energy reaching the cliff toe can be then estimated as

$\frac{d E}{d \Omega(t)}=c_{1}$

Influence of erosion rate on platform width.

Platform width is defined after Sunamura (1992) for the two main types of shore platforms, namely sloping platforms and near-horizontal platforms. Sloping platforms, which most notably occur in meso to macro-tidal areas, slope continuously $\left(1^{\circ}\right.$ to $10^{\circ}$ slope) from the cliff toe beneath sea level. Near horizontal platforms $\left(<1^{\circ}\right.$ slope $)$, mainly occur in micro-tidal and low meso-tidal environments and which are characterized by an abrupt scarp at their outer edge. In either case the platform width is defined as the horizontal distance between the sea-edge of the platform and the cliff toe as shown in Error! Reference source not found.. At any instant of time the platform width can be estimated as the sum of the initial platform width and the added platform due to backwearing erosion as: $w=w(t=0)+E(t)$. The change of platform width relative to erosion rate is obtained from this relationship as: $d w / d E=+1$.

Influence of width platform on energy reaching the cliff toe. 
The simple analytical solution developed by Gerritsen (2011) that relates the wave energy with the distance to the seaward limit of the shore platform is used here (Eq. 5). This solution is valid for platforms of about constant water depth and at the region where bottom friction can be neglected.

$H(x)=H(0) \exp \left(-\frac{B}{A}\right)$

Where $H(0)$ is the reference wave height at a reef-edge, $x$ is the distance from the reef-edge and the coefficients $A$ and $B$ are;

$A=\frac{1}{4} \rho g C_{g} \approx \frac{1}{4} \rho g C$

$B=\frac{\xi \rho g}{4 \sqrt{2} T}$

Coefficient $\xi$ is of an order of magnitude one and is given by

$\xi=\frac{\alpha H_{*} \sqrt{2+H_{*}}}{F_{r} \sqrt{1+H_{*}}}$

in which

$F_{r}=\frac{C}{\sqrt{g h(x)}}$ and $H_{*}=\frac{H(x)}{h(x)}$

where $C$ is the phase velocity that satisfies the dispersion relationship and $h(x)$ is the water depth over the shore platform, $\alpha$ is the breaking coefficient that describes the deviation of actual breaking from the periodic bore form on the $\mathrm{O}(1)$.

The change of energy reaching the cliff toe with platform width is obtained as the difference between the energy at the seaward edge of the platform and the energy at the cliff toe for different platform widths. The cliff is assumed to retreat, while maintaining a constant platform slope. The energy reaching the cliff toe has been estimated by Eq. (5) for an eroding platform of $1^{\circ}, 5^{\circ}$ and $10^{\circ}$ slope. Equation (5) is an implicit equation (i.e. $\mathrm{H}(\mathrm{x})$ is at both sides of the equation) that has been solved numerically using the MATLAB solve function. The water depth at the seaward edge, $d o$, has been assumed equal to $4.5 \mathrm{~m}$. Wave height at the seaward limit, $\mathrm{Ho}$, has been assumed equal to the maximum wave height before breaking to ensure that waves were breaking at seaward platform edge and $\mathrm{T}=10 \mathrm{~s}$.
The breaking coefficient is assumed $\alpha=0.8$ and the decay of wave height has been estimated for a range of platform width values from $1 \mathrm{~m}$ to $x=d o / \tan ($ slope). Equation (5) is an approximation that is valid where wave breaking dominates the bottom friction. From Massel and Gourlay (2000) this dominance can be assessed by the non-linearity index assuming that the representative platform water depth, $h_{r}$, is the mean water depth from seaward edge to platform width. For the presented set-up, values of $F_{c o}$ vary between 700 up and 2400, indicating that wave breaking dominates the bottom friction for all cases, and therefore supports the validity of the approximation.

Figure 9 shows the variation of wave energy reaching the cliff toe for different platform widths. The energy gradient has been obtained from solutions of Eq. (5), converting wave height into wave energy by Eq. (2), given $\rho=1024 \mathrm{~kg} / \mathrm{m}^{3}$ and $\mathrm{g}=9.81 \mathrm{~m}^{2} / \mathrm{s}$. As expected, the maximum gradients of energy dissipation with platform width are obtained for the steeper slope, $\mathrm{O}\left(-500 \mathrm{~J} / \mathrm{m}^{4}\right)$, and the smaller for the gentle slope, $\mathrm{O}\left(-50 \mathrm{~J} / \mathrm{m}^{4}\right)$, being the $5^{\circ}$ slope in between with $\mathrm{O}\left(-300 \mathrm{~J} / \mathrm{m}^{4}\right)$. For a given platform width of, for instance $25 \mathrm{~m}$, the energy decrease is maximum for the slope of $10^{\circ}$, and two and three orders of magnitude bigger than for platforms of slope $5^{\circ}$ and $1^{\circ}$ respectively, which is consistent with results presented by Thornton and Guza (1982). To assess the sensitivity of these results to different wave periods, the above estimation was made for wave periods of $5 \mathrm{~s}$ and 30s. Similar orders of magnitude were found (not shown). It is noticed that the non-linearity index for the $5 \mathrm{~s}$ waves was within the region where breaking does not dominate bottom friction $\left(F_{c o}<450\right)$, meaning that the approximation from Eq. (5) overestimates the dissipation rates.

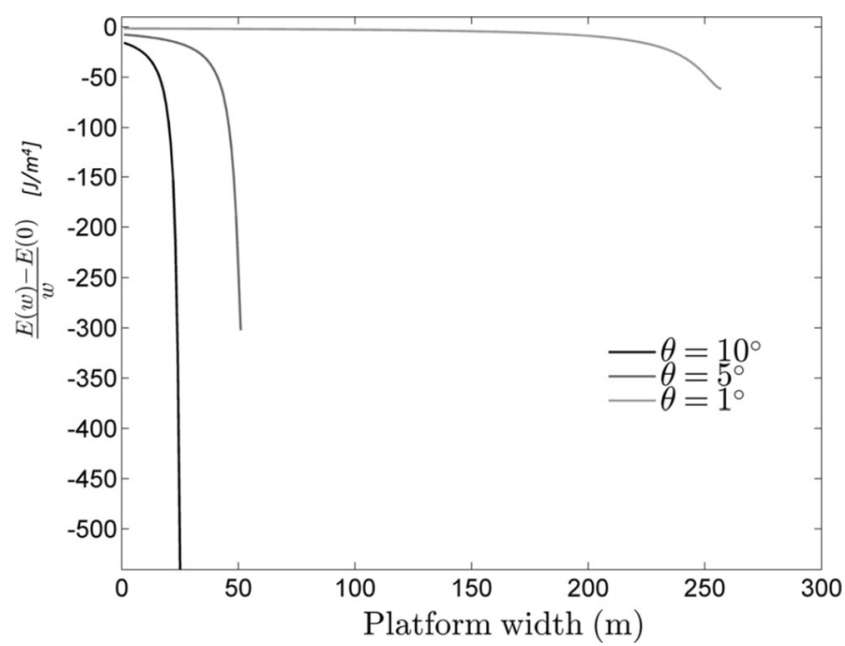

Fig. 9 Variation of wave energy derived from solving Eq. (5) for eroding platforms with slopes of 10,5 and $1 \mathrm{deg}$. The rate of energy dissipation per unit of platform width is estimated as the ratio between the difference between the energy at a given distance from the seaward edge and the energy at the seaward edge divided by the platform width 
Figure 10 summaries the feedback factor strength of the cliff toe energy depletion loop derived from the above estimates. A range of $g$ values from $\sim-10^{-10}$ to $\sim-10^{-4}$ is obtained as the product of all partial derivatives that determines the loop strength. The six order of magnitude difference between the minimum and maximum estimated values is mostly due to the geometry of the retreating platform. A nearly horizontal retreating platform $\left(1^{\circ}\right.$ slope $)$ presents the minimum absolute $g$ value of $-10^{-10}$, which corresponds with a total effect of about 1 (i.e. total effect is equal to the direct effect). A sloping platform $\left(10^{\circ}\right.$ slope) presents the maximum absolute value of $\mathrm{g}$ of $-10^{-4}$ which corresponds to a total effect of about 0.9999 (i.e. total effect is slightly smaller than the direct effect). The important of these differences for modelling cliff toe position over decades and longer is discussed in the following section.

\section{Discussion}

Based on a literature review, we have described the morphodynamic feedback structure of eroding rocky shores with a cliff and shore platform (Fig. 7.). The backwearing erosion rate (i.e. cliff horizontal erosion) has been found to be controlled by at least four feedback loops, three balancing (cliff toe energy depletion, ground water pore pressure diminution and cliff deposit protection) and one positive loop (abrasion enhancement loop). The downwearing erosion rate (i.e. vertical erosion) has been found to be controlled by at least three balancing feedback loops (weathering limited, shear depletion, cover-protection) and one positive loop (abrasion enhancement loop). Mean sea level influences the

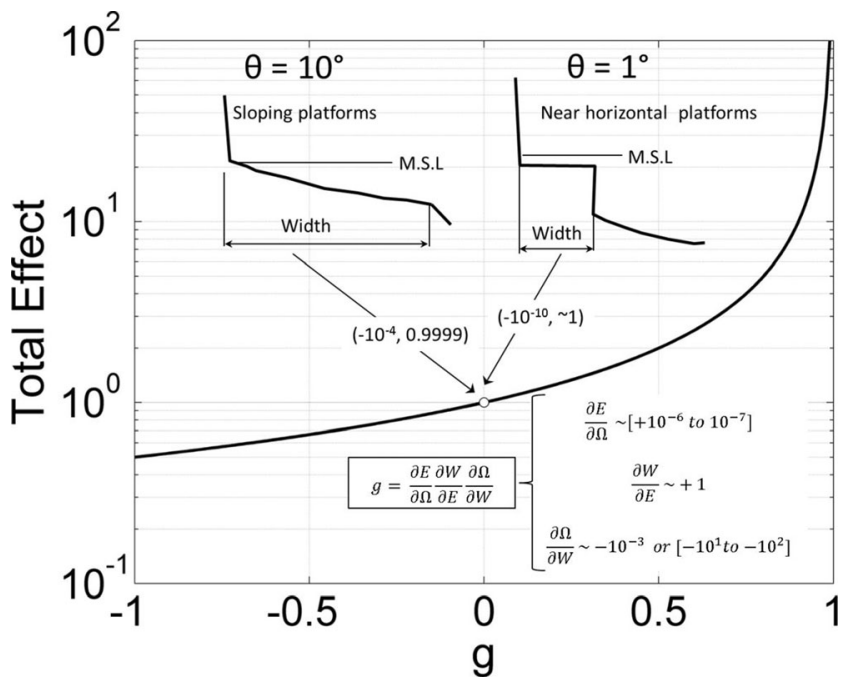

Fig. 10 Feedback factor strength, g, of a widening platform. A sloping platform has an absolute $g$ value up to six orders of magnitude bigger than a nearly horizontal shore platform but always less than $|1|$ downwearing rate through the water depth relative to the wave base, and indirectly the backwearing erosion rate through the wave energy dissipation that determines the amount of energy reaching the cliff toe. The influence of platform geometry (elevation, gradient) is acknowledged by the links among the offshore wave non-linearity parameter and the energy at cliff toe and water depth relative to wave base. The knowledge gap on our understanding of how cliff and shore platform geometry influences the morphodynamic is acknowledged by an influence link between the mass content and the offshore wave non-linearily parameter.

If mean sea level remains unchanged, the dominance of balancing feedbacks on the overall feedback structure suggest that mass wasting erosion rate is unlikely to increase but similar, or even smaller, erosion rates are anticipated to be observed in the future. This is consistent the conclusions of Ashton et al. (2011) suggesting that the damped feedback system is the most likely cliff and shore platform behaviour. A negative feedback system only requires that, if sea level were to stay constant, the erosion rate would slow down over time. How much will be slow down over time is controlled by the strength of the overall feedback factor. An exception to this behaviour is anticipated when the abrasion enhancement loop is dominant. In this scenario, the erosion rate will increase over time rather than remaining similar or decreasing. Eroded material from the cliff increases the abrasion capacity further increasing the erosion. In cliffed environments, such as response could occur at a location where the profile is covered by mobile sediment in amounts not enough to protect the cliff and shore platform such a cliff fronted by narrow platforms (Fig. 1, panel 2).

If mean sea level rises, both the geometry of cliff and shore platform and rate of sea level will determine the overall negative or positive feedback on the mass wasting erosion rate. A steeper cliff and shore platform elevation gradient will induce an increase on the downwearing due to an increase on the wave energy dissipation rate. A steeper shore platform is more effective dissipating wave energy which could reduce the energy reaching the cliff toe. An increase on mean sea level could also reduce the downwearing rate by increasing the water depth relative to the wave base. Arguably, the overall dominance of these two effects will be determined by the change on the offshore wave non-linearilty parameter, which remains largely unknown.

The characterization of cliff and shore platform mass wasting rate into an horizontal and vertical component is not a clear cut in the processes space (i.e. energy dissipation influences both local downwearing but also backwearing) but provides a convenient picture of main loops at different stages of development. For example, Dickson (2006) and Trenhaile and Kanyaya (2007) suggested that backwearing due to waves is likely to be dominant at early stages of platform development, whereas weathering processes may 
become more dominate at latter stages (i.e. function of intertidal exposure time). Accordingly, the strength of the feedback loops that control the two erosion rate components will be different at different stages of development. Anticipating how the strength of different loops varies with the geometry and environmental conditions is then critical to capture this dynamical shift and transient response.

We have estimated the strength of the cliff toe energy depletion loop which, due to the assumptions and data used, represents only a sub-set of all possible cliffed environments. In particular the estimated feedback strength would represent any coast where slope retreat is controlled by the wave activity at the toe. This applies over time scales encompassing multiple cycles of slumping and toe erosion. As noted by Hackney et al. (2013) the decrease of correlation for the harder material within their dataset might indicate that the 10 years' time used to compute the erosion rates might be too short. We have assumed that the cliff retreats while keeping the platform slope constant. This is usually the case for near horizontal shore platforms. For sloping shore platforms it will be valid after the first cycles of slumping and toe erosion where shore platform slope quickly decreases until dynamic equilibrium is reached (i.e. toe retreat but keeping the platform width constant) (Dickson et al. 2013).

The strength of the platform widening loop has been found to be $\mathrm{O}\left(-10^{-4}\right.$ to $\left.-10^{-10}\right)$ which corresponds to a total effect within $\mathrm{O}(0.9999$ to $\sim 1)$. To assess the importance of this feedback on the future erosion rates, an order of magnitude of the time scales at which the difference between a model with and without the feedback included can be estimated. The erosion rates ranges from $0.34 \mathrm{~m} \cdot \mathrm{a}^{-1}$ to $0.75 \mathrm{~m} \cdot \mathrm{a}^{-1}$ with an uncertainty of $\mathrm{O}\left( \pm 0.01 \mathrm{~m} \cdot \mathrm{a}^{-1}\right.$ to $\pm 0.16 \mathrm{~m} \cdot \mathrm{a}^{-1}$ ) (see Table 1, from Hackney et al. 2013). The difference between the erosion rates with and without the feedback is $\mathrm{O}[0.75(1-$ 0.999) $\sim 10^{-4}$ ] which is well within the uncertainty of the erosion rates. Since this decrease is not randomly distributed but consistent over time, by taking into account the cliff toe energy depletion loop, a systematic reduction of the erosion will eventually occur over large time scales. The differences between the estimated erosion with and without the feedback will be bigger than the actual position uncertainty, $(\mathrm{O}( \pm 1.5 \mathrm{~m})$ from Table 2 in Hackney et al. 2013), by times scales on the order of 2000 to 4500 years. Other feedback loops, such as the beach cover protection loop have been found to have shorter associated time scales, suggesting stronger feedback strengths. For example, Fig. 18 of Walkden and Hall (2011) shows how different beach volumes have a long term effect on recession rate appreciable over time scales of less than 1000 years.

The strength of the cliff toe energy depletion loop has been estimated assuming that the wave energy in the gravity frequency band decays exponentially shoreward of the seaward edge which might not be always the case. Dickson et al. (2013) proposed four potential mechanisms through which infragravity waves might contribute to cliff recession on micro-tidal and lower meso-tidal coasts. Infragravity waves could potentially influence the cliff erosion rate by increasing the water elevation at the cliff toe and along the platform and therefore affecting both the wetting and drying but also the amount of gravity wave energy that could reach the cliff toe. These effects could be included into the feedback structure shown in Fig. 7 through the offshore wave non-linearity state variable. Both, the energy dissipation due to wave breaking and the wave set-up have been found to increase with the offshore wave non-linearity index (Massel and Gourlay 2000). While the effect of infragravity waves may drive cliff retreat over much greater distances than by gravity waves alone, this remains to be proven. Likewise, whether the strength of the cliff toe energy depletion loop could be either reinforced or counterbalanced by the interaction between infragravity and gravity waves remains to be fully understood.

\section{Conclusions}

As coastal evolution models for rocky coasts become increasingly complex, it is important to have a basic theoretical framework of how different processes interact with each other and influence the changes and responses to interventions at different stages of development. Here we have shown how a core set of processes and feedback loops can be already distilled from the existing literature. This provides an evidence linked map of how rock coast morphodynamics is being conceptualized and where the knowledge gaps remain. We have explicitly shown how mass wasting of the cliff and shore platform is the result of a few balanced feedback loops (cliff toe energy depletion, pore pressure diminution loop, weathering limited, shear depletion, cliff and platform protection loop) but also reinforcing loops (i.e. abrasion enhancement). The changes and responses to interventions and accelerated sea level rise of a rocky coast will vary with the strength of the different feedback loops at different time epochs. While feedback strength metrics have become customary in other fields, such as global climate modelling, they remain under early stages of development in coastal geomorphology. To continue this development, the strength of a single feedback loop (cliff toe energy depletion loop) has been estimated by reasoning on the current understanding of its causal pathway. In particular, the strength of this loop under dynamical balance (i.e. where the cliff retreats while keeping the platform slope constant) with waves at the gravity frequency band has been found to be $\mathrm{O}\left(-10^{-4}\right.$ to $\left.-10^{-10}\right)$. The absolute feedback strength increases with the platform slope, being about two orders of magnitude bigger for sloping platforms than for nearly-horizontal eroding platforms but always much smaller than $|-1|$. If dominant, the time scale at which the influence of 
the feedback would be identifiable, based on the current cliff toe measurement uncertainty and limited field data, is $\mathrm{O}(>2000$ years $)$ suggesting that other feedbacks, such as the beach cover protection, might be more important for a cliff retreating with constant slope.

The analyses presented here builds on other existing theoretical frameworks (i.e. Basal End Point Control, Accumulated Excess Energy, offshore non-linearity, cliff behaviour) of often separated disciplines on an exercise of synthesis and acts as an aid for better informed quantitative morphodynamic modelling. By understanding how the individual and overall feedback strengths are influenced by different future environmental and human intervention scenarios we could provide better assessment at the time scales needed for coastal management.

Acknowledgments This research was funded by UK National Environmental Research Council (http://www.nerc.ac.uk) with support from the Environment Agency (http://environment-agency.gov.uk) as part of the project: iCOASST. Integrating Coastal Sediment Systems.

\section{Appendix: List of symbols}

\begin{tabular}{|c|c|c|}
\hline $\mathrm{g}$ & Feedback factor & $\begin{array}{l}\text { value between }-\alpha \text { and } 1 \text {, representing how } \\
\text { much times the direct effect is reduced } \\
\text { amplified by a negative/positive feed- } \\
\text { back loop }\end{array}$ \\
\hline$F_{c o}$ & $\begin{array}{l}\text { Offshore non-linearity } \\
\text { wave parameter }\end{array}$ & $\begin{array}{l}\text { non dimensional number named after } \\
\text { Swart and Loubser (1979) representing } \\
\text { the dominance of wave reflection over } \\
\text { transmission/dissipation over a given } \\
\text { platform geometry }\end{array}$ \\
\hline$E$ & $\begin{array}{l}\text { Cliff backwearing } \\
\text { erosion rate }\end{array}$ & $\begin{array}{l}\text { amount of erosion (m) during the time } \\
\text { interval } \mathrm{t}\end{array}$ \\
\hline$\Omega$ & Wave energy & $\begin{array}{l}\text { applied averaged wave energy }\left(\mathrm{J} / \mathrm{m}^{3}\right) \text { per } \\
\text { unit of surface area }\end{array}$ \\
\hline$\Omega_{c}$ & $\begin{array}{l}\text { Threshold wave } \\
\text { energy }\end{array}$ & $\begin{array}{l}\text { minimum wave energy }\left(\mathrm{J} / \mathrm{m}^{3}\right) \text { required to } \\
\text { initiate cliff erosion }\end{array}$ \\
\hline$w(t)$ & Platform width & $\begin{array}{l}\text { time dependent representative platform } \\
\text { width }\end{array}$ \\
\hline$\theta$ & Platform slope & platform slope (degrees) \\
\hline
\end{tabular}

\section{References}

Ashton AD, Walkden MJA, Dickson ME (2011) Equilibrium responses of cliffed coasts to changes in the rate of sea level rise. Mar Geol 284:217-229. doi:10.1016/j.margeo.2011.01.007

Castedo R, Fernández M, Trenhaile AS, Paredes C (2012) Modeling cyclic recession of cohesive clay coasts: effects of wave erosion and bluff stability. Mar Geol. doi:10.1016/j.margeo.2012.11.001

Dickson ME (2006) Shore platform development around Lord Howe Island, southwest Pacific. Geomorphology 76(3):295-315
Dickson ME, Ogawa H, Kench PS, Hutchinson A (2013) Sea-cliff retreat and shore platform widening: steady-state equilibrium? Earth Surface Processes and Landforms 38(9):1046

Ford MR, Becker JM, Merrifield MA (2012) Reef flat wave processes and excavation pits: observations and implications for Majuro atoll Marshall Islands. J of Coast Res 29:545-554. doi:10.2112/ JCOASTRES-D-12-00097.1

Ford MR, Becker JM, Merrifield MA (2013) Reply to: Payo, A. and Muñoz-Perez, J.J., 2013. Discussion of: Ford, M.R.; Becker, J.M., and Merrifield, M.A., 2013. Reef Flat Wave Processes and Excavation Pits: Observations and Implications for Majuro Atoll, Marshall Islands, Journal of Coastal Research, 29(3):545554; Journal of Coastal Research, 29(5), 12411246 Journal of Coastal Research 29:1243-1246 doi:10.2112/13A-00001.1

Fort D, Clark A, Cliffe D (2000) The investigation and monitoring of coastal landslides at Barton-on-Sea, Hampshire, UK. In: EN Bromhead NDaM-LI (ed) Landslides: in research, theory and practice. pp 557-572

Gerritsen F (2011) Wave attenuation and wave set-up on a coastal reef. In: Coastal Engineering Proceedings vol 17. doi:10.9753/icce.v17

Hackney C, Darby SE, Leyland J (2013) Modelling the response of soft cliffs to climate change: a statistical, process-response model using accumulated excess energy. Geomorphology. doi:10.1016/j. geomorph.2013.01.005

Harte J (2001) Consider a cylindrical cow : more adventures in environmental problem solving. University Science, Sausalito, Calif

Klocke D, Quaas J, Stevens B (2013) Assessment of different metrics for physical climate feedbacks observational. Theor and Comput Res on the Clim Syst 41:1173-1185. doi:10.1007/s00382-013-1757-1

Lane DC (2000) Diagramming conventions in system dynamics. J Oper Res Soc 51:241-245

Lane SN (2013) 21st century climate change: where has all the geomorphology gone? Earth Surf Process Landf 38:106-110. doi:10.1002/ esp. 3362

Massel SR, Gourlay MR (2000) On the modelling of wave breaking and set- up on coral reefs. Coast Eng 39:1-27. doi:10.1016/S03783839(99)00052-6

Masselink G, Russell P (2010) Coastal erosion in MCCIP annual report card 2010-11, MCCIP Science Review

Murray AB, Ashton AD (2013) Instability and finite-amplitude selforganization of large-scale coastline shapes. Philos trans Ser A Math, phys, and eng sci 371:20120363

Naylor LA, Stephenson WJ (2010) On the role of discontinuities in mediating shore platform erosion. Geomorphology 114:89-100. doi:10.1016/j.geomorph.2008.12.024

Naylor LA, Stephenson WJ, Trenhaile AS (2010) Rock coast geomorphology: recent advances and future research directions. Geomorphology 114:3-11. doi:10.1016/j.geomorph.2009.02.004

Ogawa H (2012) Wave Characteristics and Transformations on Subhorizontal (type B) Shore Platforms on the East Coast of the North Island, New Zealand. Geography)-University of Auckland

Payo A, Muñoz-Perez JJ (2013) Discussion of Ford, M.R.; Becker, J.M., and Merrifield, M.A. 2013. Reef Flat Wave Processes and Excavation Pits: Observations and Implications for Majuro Atoll, Marshall Islands. Journal of Coastal Research, 29(3), 545554 Journal of Coastal Research 29:1236-1242 doi:10.2112/ JCOASTRES-D-13-00051.1

Phillips JD (2006) Deterministic chaos and historical geomorphology: a review and look forward. Geomorphology 76:109-121. doi:10. 1016/j.geomorph.2005.10.004

Phillips JD (2009) Changes, perturbations, and responses in geomorphic systems. Progress in Physical Geography 33(1):17-30

Porter NJ, Trenhaile AS, Prestanski KJ, Kanyaya JI (2010) Shore platform downwearing in eastern Canada: micro-tidal gaspé Québec. Geomorphology 116:77-86. doi:10.1016/j.geomorph.2009.10.010 
Robinson L (1977) Erosive processes on the shore platform of northeast Yorkshire England. Mar Geol 23:339-361

Slingerland R (1981) Qualitative stability analysis of geologic systems, with an example from river hydraulic geometry. Geology 9:491-493

Stephenson WJ (2000) Shore platforms: a neglected coastal feature? Prog Phys Geogr 24:311-327. doi:10.1177/030913330002400301

Stephenson WJ, Kirk RM (2000) Development of shore platforms on kaikoura peninsula south island, New Zealand: part One: the role of waves. Geomorphology 32:21-41. doi:10.1016/S0169-555X(99) 00061-6

Sunamura T (1992) Geomorphology of rocky coasts. Coastal morphology and research Y. Wiley, Chichester

Sunamura T (1994) Rock control in coastal geomorphic processes vol 15. Trans — Jpn Geomorphol Union. doi:10.1016/0148-9062(95) 90026-2

Swart D, Loubser C (1979) Vocoidal wave theory, Vol. 2: verification Coastal Engineering and Hydraulics Division, National Research Institute for Oceanology, Council for Scientific and Industrial Research, Republic of South Africa, Research Report
Thornton EB, Guza RT (1982) Energy saturation and phase speeds measured on a natural beach. J of Geophys Res: Oceans 87:9499 9508. doi:10.1029/JC087iC12p09499

Trenhaile AS (2005) Modelling the effect of waves, weathering and beach development on shore platform development. Earth Surf Process Landf 30:613-634

Trenhaile AS (2008) Modeling the role of weathering in shore platform development. Geomorphology 94:24-39. doi:10.1016/j.geomorph. 2007.04.002

Trenhaile AS (2010) Modeling cohesive clay coast evolution and response to climate change. Mar Geol 277:11-20. doi:10.1016/j. margeo.2010.08.002

Trenhaile AS, Kanyaya JI (2007) The role of wave erosion on sloping and horizontal shore platforms in macro- and mesotidal environments. J Coast Res 23:298-309. doi:10.2112/04-0282.1

Walkden MJA, Hall JW (2005) A predictive mesoscale model of the erosion and profile development of soft rock shores. Coast Eng 52: 535-563. doi:10.1016/j.coastaleng.2005.02.005

Walkden MJ, Hall JW (2011) A mesoscale predictive model of the evolution and management of a soft- rock coast. J Coast Res 27: 529-543. doi:10.2112/JCOASTRES-D-10-00099.1 